University of New England

DUNE: DigitalUNE

$1-3-2019$

Weak Effects Of Geolocators On Small Birds: A Meta-Analysis

Controlled For Phylogeny And Publication Bias

Vojtěch Brlík

Noah G. Perlut

Follow this and additional works at: https://dune.une.edu/env_facpubs

Part of the Ornithology Commons 


\section{Weak effects of geolocators on small birds: A meta-analysis controlled for phylogeny and publication bias}

Vojtěch Brlík $^{1,2}$ (D) | Jaroslav Koleček ${ }^{1}$ (D) | Malcolm Burgess ${ }^{3}$ (D) | Steffen Hahn ${ }^{4}$ (D) |

Diana Humple $^{5}$ | Miloš Krist ${ }^{6}$ (D) | Janne Ouwehand ${ }^{7}$ (D) | Emily L. Weiser ${ }^{8,9}$ (D)

Peter Adamík $^{6,10}$ (D) | José A. Alves ${ }^{11,12}$ (D) | Debora Arlt ${ }^{13}$ (iD | Sanja Barišićc ${ }^{14}$ (iD

Detlef Becker $^{15}$ | Eduardo J. Belda ${ }^{16}$ (D) | Václav Beran 6,17,18 | Christiaan Both7 (D) |

Susana P. Bravo $^{19}$ | Martins Briedis ${ }^{4}$ | Bohumír Chutný $^{20}$ | Davor Ćiković14 (iD |

Nathan W. Cooper ${ }^{21}$ (D) | Joana S. Costa ${ }^{11}$ (iD | Víctor R. Cueto ${ }^{19}$

Tamara Emmenegger ${ }^{4}$ (D) | Kevin Fraser ${ }^{22}$ | Olivier Gilg ${ }^{23,24}$ (D) | Marina Guerrero ${ }^{25}$ |

Michael T. Hallworth $^{26}$ (D) | Chris Hewson ${ }^{27}$ (D) | Frédéric Jiguet ${ }^{28}$ (D) |

James A. Johnson ${ }^{29}$ | Tosha Kelly ${ }^{30}$ ｜Dmitry Kishkinev ${ }^{31,32}$ (D) | Michel Leconte ${ }^{33}$ |

Terje Lislevand $^{34}$ (D) | Simeon Lisovski ${ }^{4}$ (D) | Cosme López ${ }^{35}$ | Kent P. McFarland ${ }^{36}$ (D) |

Peter P. Marra ${ }^{26}$ | Steven M. Matsuoka ${ }^{29,37}$ | Piotr Matyjasiak ${ }^{38}$ (D) |

Christoph M. Meier ${ }^{4}$ (D) | Benjamin Metzger ${ }^{39}$ | Juan S. Monrós ${ }^{40}$ | Roland Neumann ${ }^{41}$ |

Amy Newman $^{42}$ | Ryan Norris ${ }^{42}$ | Tomas Pärt ${ }^{13}$ iD | Václav Pavel ${ }^{6,43}$ | Noah Perlut ${ }^{44}$ |

Markus Piha 45 (D) | Jeroen Reneerkens ${ }^{7}$ (D) | Christopher C. Rimmer ${ }^{36}$ |

Amélie Roberto-Charron $^{22}$ | Chiara Scandolara ${ }^{4}$ | Natalia Sokolova ${ }^{46,47}$ (D) |

Makiko Takenaka $^{48}$ | Dirk Tolkmitt ${ }^{49}$ | Herman van Oosten ${ }^{50,51}$ |

Arndt H. J. Wellbrock ${ }^{52}$ (D) | Hazel Wheeler ${ }^{53}$ | Jan van der Winden ${ }^{54}$ |

Klaudia Witte ${ }^{52}$ (D) Bradley K. Woodworth ${ }^{55}$ (D) | Petr Procházka ${ }^{1}$ (D)

Correspondence

Vojtěch Brlík

Email: vojtech.brlik@gmail.com

Funding information

Institut Polaire Français Paul Emile

Victor, Grant/Award Number: IPEV-

1036; Leverhulme Trust, Grant/Award

Number: RPG-2013288; Russian Science

Foundation, Grant/Award Number:

17-14-01147; Russian Foundation for

Basic Research, Grant/Award Number:

Arctic-18-05-60261; Grantová Agentura

České Republiky, Grant/Award Number:

13-06451S; Institutional Research Plan,

Grant/Award Number: RVO: 68081766
Abstract

1. Currently, the deployment of tracking devices is one of the most frequently used approaches to study movement ecology of birds. Recent miniaturization of lightlevel geolocators enabled studying small bird species whose migratory patterns were widely unknown. However, geolocators may reduce vital rates in tagged birds and may bias obtained movement data.

2. There is a need for a thorough assessment of the potential tag effects on small birds, as previous meta-analyses did not evaluate unpublished data and impact of multiple life-history traits, focused mainly on large species and the number of published studies tagging small birds has increased substantially. 
3. We quantitatively reviewed 549 records extracted from 74 published and 48 unpublished studies on over 7,800 tagged and 17,800 control individuals to examine the effects of geolocator tagging on small bird species (body mass $<100 \mathrm{~g}$ ). We calculated the effect of tagging on apparent survival, condition, phenology and breeding performance and identified the most important predictors of the magnitude of effect sizes.

4. Even though the effects were not statistically significant in phylogenetically controlled models, we found a weak negative impact of geolocators on apparent survival. The negative effect on apparent survival was stronger with increasing relative load of the device and with geolocators attached using elastic harnesses. Moreover, tagging effects were stronger in smaller species.

5. In conclusion, we found a weak effect on apparent survival of tagged birds and managed to pinpoint key aspects and drivers of tagging effects. We provide recommendations for establishing matched control group for proper effect size assessment in future studies and outline various aspects of tagging that need further investigation. Finally, our results encourage further use of geolocators on small bird species but the ethical aspects and scientific benefits should always be considered.

\section{KEYWORDS}

condition, migration, phenology, reproduction, return rate, survival, tag effect, tracking device

${ }^{1}$ Institute of Vertebrate Biology, The Czech Academy of Sciences, Brno, Czech Republic; ${ }^{2}$ Department of Ecology, Faculty of Science, Charles University, Prague, Czech Republic; ${ }^{3}$ Royal Society for the Protection of Birds-Centre for Conservation Science, The Lodge, Sandy, UK; ${ }^{4}$ Bird Migration Department, Swiss Ornithological Institute, Sempach, Switzerland; ${ }^{5}$ Point Blue Conservation Science, Petaluma, California; ${ }^{6}$ Department of Zoology, Faculty of Science, Palacký University, Olomouc, Czech Republic; ${ }^{7}$ Conservation Ecology Group, Groningen Institute for Evolutionary Life Sciences, University of Groningen, Groningen, The Netherlands; ${ }^{8}$ Division of Biology, Kansas State University, Manhattan, Kansas; ${ }^{9}$ U.S. Geological Survey, Upper Midwest Environmental Sciences Center, La Crosse, Wisconsin; ${ }^{10}$ Museum of Natural History, Olomouc, Czech Republic; ${ }^{11}$ Department of Biology and Centre for Environmental and Marine Studies, University of Aveiro, Campus Universitário de Santiago, Aveiro, Portugal; ${ }^{12}$ South Iceland Research Centre, University of Iceland, Laugarvatn, Iceland; ${ }^{13}$ Department of Ecology, Swedish University of Agricultural Sciences, Uppsala, Sweden; ${ }^{14}$ Institute of Ornithology, Croatian Academy of Sciences and Arts, Zagreb, Croatia; ${ }^{15}$ Museum Heineanum, Halberstadt, Germany; ${ }^{16}$ Universitat Politècnica de València, Valencia, Spain; ${ }^{17}$ Municipal Museum of Ústí nad Labem, Ústí nad Labem, Czech Republic; ${ }^{18}$ ALKA Wildlife o.p.s., Dačice, Czech Republic; ${ }^{19}$ CIEMEP, CONICET/UNPSJB, Chubut, Argentina; ${ }^{20}$ Prague 10, Czech Republic; ${ }^{21}$ Migratory Bird Center, Smithsonian Conservation Biology Institute, National Zoological Park, Washington, District of Columbia; ${ }^{22}$ Avian Behaviour and Conservation Lab, Department of Biological Sciences, University of Manitoba, Winnipeg, Manitoba, Canada; ${ }^{23} \mathrm{UMR} 6249$ ChronoEnvironnement, Université de Bourgogne Franche-Comté, Besançon, France; ${ }^{24}$ Groupe de recherche en Ecologie Arctique, Francheville, France; ${ }^{25}$ Servicio de Jardines, Bosques y Huertas, Patronato de la Alhambra y el Generalife, Granada, Spain; ${ }^{26}$ Migratory Bird Center-Smithsonian Conservation Biology Institute, National Zoological Park, Washington, District of Columbia; ${ }^{27}$ British Trust for Ornithology, The Nunnery, Thetford, UK; ${ }^{28}$ UMR7204 CESCO, MNHNCNRS-Sorbonne Université, CP135, Paris, France; ${ }^{29}$ U.S. Fish and Wildlife Service, Migratory Bird Management, Anchorage, Alaska; ${ }^{30}$ Advanced Facility for Avian Research, Western University, London, Ontario, Canada; ${ }^{31}$ School of Natural Sciences, Bangor University, Bangor, UK; ${ }^{32}$ Biological station Rybachy, Zoological Institute of Russian Academy of Sciences, Rybachy, Russia; ${ }^{33}$ Quartier du Caü, Arudy, France; ${ }^{34}$ Department of Natural History, University Museum of Bergen, University of Bergen, Bergen, Norway; ${ }^{35}$ Department of Zoology, Faculty of Biology, Universidad de Sevilla, Seville, Spain; ${ }^{36}$ Vermont Center for Ecostudies, Norwich, Vermont; ${ }^{37}$ U.S. Geological Survey Alaska Science Center, Anchorage, Alaska; ${ }^{38}$ Department of Evolutionary Biology, Faculty of Biology and Environmental Sciences, Cardinal Stefan Wyszyński University in Warsaw, Warsaw, Poland; ${ }^{39}$ Lisbon, Portugal; ${ }^{40}$ Cavanilles Institute of Biodiversity and Evolutionary Biology, University of Valencia, Paterna, València, Spain; ${ }^{41}$ Stäbelow, Germany; ${ }^{42}$ Department of Integrative Biology, University of Guelph, Guelph, Ontario, Canada; ${ }^{43}$ Centre for Polar Ecology, University of South Bohemia, České Budějovice, Czech Republic; ${ }^{44}$ Department of Environmental Studies, University of New England, Biddeford, Maine; ${ }^{45}$ Finnish Museum of Natural History LUOMUS, University of Helsinki, Helsinki, Finland; ${ }^{46}$ Arctic Research Station of Institute of Plant and Animal Ecology, Ural Branch Russian Academy of Sciences, Labytnangi, Russia; ${ }^{47}$ Arctic Research Center of Yamal-Nenets Autonomous District, Salekhard, Russia; ${ }^{48}$ Tokai University Sapporo Campus, Hokkaido, Japan; ${ }^{49}$ Leipzig, Germany; ${ }^{50}$ Oenanthe Ecologie, Wageningen, The Netherlands; ${ }^{51}$ Institute for Water and Wetland Research, Animal Ecology, Physiology and Experimental Plant Ecology, Radboud University, Nijmegen, The Netherlands; ${ }^{52}$ Institute of Biology, Department of Chemistry-Biology, Faculty of Science and Technology, University of Siegen, Siegen, Germany; ${ }^{53}$ Wildlife Preservation Canada, Guelph, Ontario, Canada; ${ }^{54}$ Ecology Research and Consultancy, Utrecht, The Netherlands and ${ }^{55}$ School of Biological Sciences, The University of Queensland, Brisbane, Queensland, Australia 


\section{1 | INTRODUCTION}

Tracking devices have brought undisputed insights into the ecology of birds. The use of these tags has enabled researchers to gather valuable information about the timing of life events across annual cycles, the year-round geographic distribution of populations and other important ecological patterns in many species whose movement ecology was widely unknown (e.g. Patchett, Finch, \& Cresswell, 2018; Stanley, MacPherson, Fraser, McKinnon, \& Stutchbury, 2012; Weimerskirch et al., 2002). A significant proportion of recently published tracking studies use light-level geolocators on small bird species (body mass up to 100 g; Bridge et al., 2013; McKinnon \& Love, 2018); however, the increasing use of these tags on small birds raises questions about ethics of tagging and how representative the behaviour of tagged individuals is (Jewell, 2013; Wilson \& McMahon, 2006).

Studies using tracking devices such as archival light-level geolocators (hereafter "geolocators") frequently report the effect of tagging. The published results on the effects of geolocator tagging are equivocal: Some found reduced apparent survival, breeding success and parental care (Arlt, Low, \& Pärt, 2013; Pakanen, Rönkä, Thomson, \& Koivula, 2015; Scandolara et al., 2014; Weiser et al., 2016) while others report no obvious effects (Bell, Harouchi, Hewson, \& Burgess, 2017; Fairhurst et al., 2015; Peterson et al., 2015; van Wijk, Souchay, Jenni-Eiermann, Bauer, \& Schaub, 2015). Recent meta-analyses evaluating the effects of geolocators (Costantini \& Møller, 2013) and other tracking devices (Barron, Brawn, \& Weatherhead, 2010; Bodey et al., 2018a) showed slightly negative effects on apparent survival, breeding success and parental care. These studies also discussed relative load as an aspect affecting the tagged birds (Costantini \& Møller, 2013), or suggested multiple threshold values of relative load on birds (Barron et al., 2010; Bodey et al., 2018a). However, these studies involved mainly large bird species where the same additional relative load will more negatively affect surplus power and thus the flight performance than in smaller species (Caccamise \& Hedin, 1985). Moreover, previous studies did not control for the effect of small-sample studies, or phylogenetic non-independence and its uncertainty. There is thus a lack of systematic and complex evaluation of geolocator effects on small birds including species' life-history and ecological traits, geolocator design, and type of attachment.

Almost all prior meta-analyses reporting effects of tagging relied only on published sources and could thus be affected by publication bias (Koricheva, Gurevitch, \& Mengersen, 2013), as omitting unpublished sources in meta-analyses may obscure the result (see, e.g. Sánchez-Tójar et al., 2018). The main source of publication bias in movement ecology could be a lower probability of publishing studies based on a small sample size, including studies where no or only few tagged birds were successfully recovered due to a strong tagging effect. Additionally, geolocator effects most frequently rely on comparisons between tagged and control birds and a biased choice of control individuals may directly lead to the misestimation of the tagging effect sizes. The bias in the control groups can be due to selection of smaller birds, birds being caught in different spatiotemporal conditions, including non-territorial individuals, or different effort put into recapturing control and tagged individuals.

The number of studies tagging small birds is rapidly increasing each year even though our understanding of tag effects is incomplete. In this study, we evaluated the effects of tagging on apparent survival, condition, phenology and breeding performance for small bird species (<100 g) in a robust dataset of both published and unpublished studies to minimize the impact of publication bias. Moreover, we assess whether the tagging effects are related to species' ecological and life-history traits, type of control treatment as well as geolocator and attachment designs. We build on the most recent advances in meta-analytical statistical modelling to get unbiased estimates of the geolocator deployment effects controlled for phylogenetic non-independence and its uncertainty (Doncaster \& Spake, 2018; Guillerme \& Healy, 2017; Hadfield, 2010; Viechtbauer, 2010).

\section{PREDICTIONS}

1. Geolocators will negatively affect apparent survival, condition, phenology and breeding performance of small birds.

2. Negative effects will be stronger in unpublished studies than in published studies.

3. Deleterious effects will be most prominent in studies establishing matched control groups compared to studies with potentially biased control groups.

4. Geolocators which constitute a higher relative load will imply stronger negative effects.

5. Geolocators with a longer light stalk/pipe will cause stronger negative effects because of increased drag in flight and thus increased energetic expenditure (Bowlin et al., 2010; Pennycuick, Fast, Ballerstädt, \& Rattenborg, 2012). These effects will be stronger in aerial foragers than in other foraging guilds (Costantini \& Møller, 2013).

6. Non-elastic harnesses will cause stronger negative effects than elastic harnesses, which better adjust to intra-annual body mass changes and avoid flight restriction (Blackburn et al., 2016).

\section{3 | MATERIALS AND METHODS}

\subsection{Data search}

We conducted a comprehensive search for both published and unpublished studies deploying geolocators on bird species with body mass up to $100 \mathrm{~g}$. We searched the Web of Science Core Collection (search terms: TS = (geoloc* AND (bird* OR avian OR migra*) OR geologg*)) and Scopus databases (search terms: TITLE-ABS-KEY (geoloc* AND (bird* OR migra*) OR geologg*)), to find published studies listed to 18 February 2018. Moreover, we searched reference lists 
of studies using geolocators on small birds and included studies from previous comparative studies (Bridge et al., 2013; Costantini \& Møller, 2013; Weiser et al., 2016). In order to obtain information from unpublished studies, we inquired geolocator producers and the Migrant Landbird Study Group to disseminate our request for unpublished study details among their customers and members, respectively. In addition, we asked the corresponding authors of the published studies to share any unpublished data. The major geolocator producers-Biotrack, Lotek, Migrate Technology and the Swiss Ornithological Institute-sent our request to their customers. To find whether the originally unpublished studies were published over the course of this study, we inspected their status on 1 December 2018. The entire process of search and selection of studies and records (described below) is presented in a flow chart (Supporting Information Figure S1).

\section{2 | Inclusion criteria; additional data requesting}

We included studies that met the following criteria:

1. The study reported response variables (e.g. return rates, body masses) necessary for effect size calculation.

2. The study included a control group of birds alongside the geolocator-tagged individuals or reported a pairwise comparison of tagged birds during geolocator deployment and recovery.

3. As a control group, the study considered birds marked on the same site, of the same sex and age class without any indication of a difference in recapture effort between tagged and control groups.

4. For pairwise comparisons, the study presented correlation coefficients or raw data.

5. The variable of interest was presented outside the interaction with another variable.

In order to obtain robust and unbiased results, we asked the corresponding authors for missing data or clarification when the criteria were not met or when it was not clear whether the study complied with the criteria ( $70 \%$ response rate $[n=115]$ ). In addition, we excluded birds that had lost geolocators before subsequent recapture as we did not know when the bird lost the geolocator, and excluded all individuals tagged repeatedly over years because of possible interannual carryover effects of the devices. $\mathrm{VBr}$ assessed all studies for eligibility and extracted data; the final dataset was cross-checked by JK and PP. A list of all published studies included in the meta-analysis is provided in the Published Data Sources section.

\section{3 | Trait categories; effect size calculation; explanatory variables}

We divided all collected data into four trait categories: apparent survival, condition, phenology and breeding performance based on the response variables reported (e.g. interannual recapture rates, body mass changes, arrival dates or clutch sizes; Supporting Information
Table S2). These categories represent the main traits possibly affected in the geolocator-tagged individuals. Subsequently, analyses were run separately for each trait category. We calculated the effect sizes for groups of tagged birds from the same study site and year of attachment, of the same sex (if applicable) and specific geolocator and attachment type accompanied with the corresponding control groups. For simplicity, we call these units records throughout the text. For each record, we extracted a contingency table with the treatment arm continuity correction (Schwarzer, Carpenter, \& Rücker, 2014) or mean, variance, and sample size, to calculate the unbiased standardized mean difference-Hedges' $g$ (Borenstein, Hedges, Higgins, \& Rothstein, 2009)-and its variance with correction for the effect of small sample sizes (Doncaster \& Spake, 2018). We used the equation from Sweeting, Sutton, and Lambert (2004) to calculate variance in pairwise comparisons. When raw data were not provided, we used the reported test statistics $\left(F, t\right.$ or $\left.\chi^{2}\right)$ and sample sizes to calculate the effect size using the $\mathrm{R}$ package compute.es (Del Re, 2013). Besides the effect size measures, we extracted additional variables of potential interest-ecological and life-history traits per species, methodological aspects of the study, geolocator and attachment designs and harness material elasticity (Table 1 ).

\subsection{Accounting for dependency}

We accounted for data non-independence on several levels. When multiple records shared one control group (e.g. several geolocator types and attachment designs used in one year), we split the sample size in the shared control group by the number of records to avoid a false increase in record precision. When multiple measures were available for the same individuals, we randomly chose one effect size measure in each trait category $(n=8)$. If the study provided both recapture and re-encounter rates, we chose the re-encounter rate as a more objective measure of apparent survival. Re-encounters included captures and observations of tagged birds, and thus, the bias towards the tagged birds caused by the potentially higher recapture effort to retrieve the geolocators should be lower. Finally, we accounted for phylogenetic non-independence between the species and the uncertainty of these relationships using 100 phylogenetic trees (Jetz, Thomas, Joy, Hartmann, \& Mooers, 2012) downloaded from the BirdTree.org (www.birdtree.org) using the backbone of Hackett et al. (2008). Moreover, we used the random intercepts of species and study sites in all models, the latter to account for possible site-specific differences (such as different netting effort or other field methods used by particular research teams).

\subsection{Overall effect sizes and heterogeneity}

We calculated the overall effect size for each trait category from all available records using meta-analytical null models. We employed the MCMCgImm function from the MCMCgImm package (Hadfield, 2010) to estimate overall effect sizes not controlled for phylogeny (model 1, Supporting Information Table S3). We then used the mulTree function from the mulTree package (Guillerme \& Healy, 2017) to 
TABLE 1 Explanatory variables used in the multivariate meta-analysis of apparent survival extracted from published and unpublished geolocator studies or from the literature. $N$ presents the number of records specified as the groups of tagged birds from the same study site, year of attachment, of the same sex and the specific geolocator and the attachment type accompanied with the corresponding control groups

\begin{tabular}{|c|c|c|}
\hline & Description & $N$ \\
\hline \multicolumn{3}{|l|}{ Methodological aspect } \\
\hline \multirow[t]{2}{*}{ Published data } & $\begin{array}{l}\text { Published-data from published studies (for details see } \\
\text { Methods), data from unpublished sources from years } \\
\text { following an already published study or data initially } \\
\text { collected as unpublished but published by } 31 \text { August } 2018\end{array}$ & 303 \\
\hline & Unpublished-data from unpublished studies & 123 \\
\hline \multirow[t]{2}{*}{ Control group } & $\begin{array}{l}\text { Matched-birds handled in the exactly same way as } \\
\text { geolocator-tagged birds except for geolocator deployment }\end{array}$ & 102 \\
\hline & $\begin{array}{l}\text { Marked only-birds of the same sex, age, from the same year } \\
\text { and study site or birds from the same site, from different } \\
\text { years }\end{array}$ & 324 \\
\hline \multicolumn{3}{|l|}{ Species trait } \\
\hline \multirow{2}{*}{$\begin{array}{l}\text { Foraging } \\
\text { strategy }^{b, c}\end{array}$} & Aerial forager & 122 \\
\hline & Non-aerial forager & 304 \\
\hline \multirow[t]{2}{*}{ Sex } & Males & 195 \\
\hline & Females & 120 \\
\hline \multicolumn{3}{|c|}{ Geolocator specification } \\
\hline Relative load & $\begin{array}{l}\% \text { of geolocator mass (including the harness) of the body mass } \\
\text { of the tagged birds }\end{array}$ & 418 \\
\hline Stalk/pipe length ${ }^{a}$ & $\begin{array}{l}\text { Length }(\mathrm{mm}) \text { of the stalk/pipe holding the light sensor or } \\
\text { guiding the light towards the sensor ( } 0 \mathrm{~mm} \text { for stalkless } \\
\text { models) }\end{array}$ & 371 \\
\hline \multicolumn{3}{|c|}{ Attachment specification } \\
\hline \multirow[t]{3}{*}{ Attachment type } & Leg-loop harness & 304 \\
\hline & Full-body harness & 80 \\
\hline & Leg-flag attachment & 42 \\
\hline \multirow[t]{2}{*}{ Material elasticity ${ }^{a}$} & $\begin{array}{l}\text { Elastic-elastan, ethylene propylene, neoprene, rubber, } \\
\text { silicone, silastic or Stretch Magic }\end{array}$ & 235 \\
\hline & Non-elastic-cord, kevlar, nylon, plastic, polyester or teflon & 146 \\
\hline \multicolumn{3}{|l|}{ Ecological trait } \\
\hline \multirow[t]{9}{*}{ Life histories } & $\begin{array}{l}\text { Great circle distance between geolocator deployment site and } \\
\text { population-specific centroid of the non-breeding (or } \\
\text { breeding) range }\end{array}$ & 426 \\
\hline & Male body mass (g) & 426 \\
\hline & Female body mass (g) & 426 \\
\hline & Nest type-open/close & 426 \\
\hline & Clutch size (number of eggs) & 426 \\
\hline & Number of broods per year & 426 \\
\hline & $\begin{array}{l}\text { Dense habitat preference (species occurs especially in dense } \\
\text { habitats, e.g. reeds or scrub)-yes/no }\end{array}$ & 426 \\
\hline & Egg mass $(g)-$ mean fresh mass ${ }^{d}$ & 426 \\
\hline & Clutch mass $(\mathrm{g})$-egg mass $\times$ clutch size & 426 \\
\hline
\end{tabular}

${ }^{\mathrm{a}}$ Only used for harness attachments. ${ }^{\mathrm{b}} \mathrm{Cramp} \&$ Perrins, 1977-1994. ${ }^{\mathrm{c}}$ Rodewald, 2015. ${ }^{\mathrm{d}}$ Schönwetter, 1960-1992. automatically fit a MCMCgImm model on each phylogenetic tree and summarised the results from all these models to obtain phylogenetically controlled overall effect size estimates (model 2, Supporting Information Table S3). We used weakly informative inverse-Gamma priors ( $\mathrm{V}=1, \mathrm{nu}=0.002)$ in all models. All fitted MCMCgImm models converged and Gelman-Rubin statistic was always $<1.1$ for all parameters. As our data contained many effect sizes based on small sample sizes, which could lead to a biased estimate of the overall effect size variance, all effect sizes were weighted by their meanadjusted sampling variance (Doncaster \& Spake, 2018). We considered effect sizes (Hedge's $g$ ) of 0.2, 0.5 and 0.8 weak, moderate and large effects, respectively. Moreover, we calculated the amount of 


\begin{tabular}{|c|c|c|c|c|c|c|}
\hline \multirow[b]{2}{*}{ Trait category } & \multicolumn{2}{|c|}{ Unpublished (\%) } & \multicolumn{4}{|c|}{ Egger's regression } \\
\hline & Effect sizes & $N$ & Intercept & $t$ & SE & $p$ \\
\hline Apparent survival & 28.9 & 426 & 0.12 & 1.53 & 0.08 & 0.121 \\
\hline Condition & 63.3 & 79 & -0.36 & -1.70 & 0.21 & 0.088 \\
\hline Phenology & 59.1 & 22 & -0.26 & -1.28 & 0.21 & 0.217 \\
\hline Breeding performance & 27.3 & 22 & -0.01 & -0.01 & 0.61 & 0.993 \\
\hline
\end{tabular}

TABLE 2 Number of unpublished effect sizes included in the analysis and Egger's regression tests of the null model residuals against their precision to assess the presence of publication bias between-study heterogeneity in all null models using the equation described in Nakagawa and Santos (2012). Phylogenetic heritability $\left(\mathrm{H}^{2}\right)$ expressing the phylogenetic signal was estimated as the ratio of phylogenetic variance $\left(\sigma_{\text {phylogeny }}^{2}\right)$ against the sum of phylogenetic and species variance $\left(\sigma_{\text {species }}^{2}\right)$ from the models (Supporting Information Table S3; Hadfield \& Nakagawa, 2010):

$$
H^{2}=\sigma_{\text {phylogeny }}^{2} /\left(\sigma_{\text {phylogeny }}^{2}+\sigma_{\text {species }}^{2}\right) .
$$

\section{6 | Multivariate meta-analysis}

To unveil the most important dependencies of the geolocator effects, we calculated three types of multivariate models: a full trait model (model 3), an ecological model (model 4) and models of publication bias (model 5, Supporting Information Table S3). In the full trait model, we used methodological, species, geolocator specification and attachment variables (Table 1 ) to estimate their impact on apparent survival (model 3). We did not compare the tagging effects of different attachment types due to their use in specific groups of species (e.g. the legflagged attachment in shorebirds or the full-body harnesses in nightjars and swifts only). Prior to fitting the ecological model, we employed a principal component analysis of the intercorrelated log continuous lifehistory traits and extracted the two most important ordination axesPC1 and PC2 (Table 1). The PC1 explained $54.4 \%$ of the variability and expressed a gradient of species characterized mainly by increasing body mass, egg mass and clutch mass (Supporting Information Figure S4). The PC2 explained $18.7 \%$ of variance and was characterized mainly by increasing clutch sizes, number of broods and decreasing migration distances (Supporting Information Figure S4). These axes together with the categorical ecological traits (Table 1) were then entered into the ecological model to estimate their effect on apparent survival (model 4). Finally, we tested for differences in effect sizes between published and unpublished results in each trait category using all available records (model 5). In these models, we employed the rma.mv function from the R package metafor (Viechtbauer, 2010) weighted by the mean-adjusted sampling error (Doncaster \& Spake, 2018). Continuous predictors were scaled and centred. None of the model residuals violated the assumptions of normal distribution. Because the phylogenetic relatedness of the species explained only a small amount of variation and the phylogenetic relatedness correlates with the life-history and ecological traits, we did not control for phylogeny in the multivariate models but incorporated the random intercepts of species and study site. We calculated $R^{2}$ for the full trait and ecological models using the residual betweenstudy variability $\left(\tau^{2}\right.$ residual $)$ and the total between-study variability $\left(\tau_{\text {total }}^{2}\right)$ according to the equation (López-López, Marín-Martínez, SánchezMeca, Van den Noortgate, \& Viechtbauer, 2014):

$$
R^{2}=\left(1-\tau_{\text {residual }}^{2} / \tau_{\text {total }}^{2}\right) \times 100
$$

\section{7 | Publication bias; body mass manipulation}

We used funnel plots to visually check for potential asymmetry caused by publication bias in each trait category (Supporting Information Figure S5). To quantify the level of asymmetry in each trait category, we applied the Egger's regression tests of the metaanalytical residuals from all null models of the trait categories (calculated using the rma.mv function) against effect size precision (1/mean-adjusted standard error; Nakagawa \& Santos, 2012). An intercept significantly differing from zero suggests the presence of publication bias. In order to find differences in log body mass between the tagged and control individuals during the tagging and marking, we applied a linear mixed-effect model with species and study site as a random intercept weighted by the sample sizes. We considered all effect sizes significant when the $95 \%$ credible interval (Crl; using MCMCgImm function) or confidence interval ( $\mathrm{Cl}$; using rma.mv function) did not overlap zero. All analyses were conducted in $\mathrm{R}$ version 3.3.1 ( $\mathrm{R}$ Core Team, 2018).

\section{4 | RESULTS}

We assessed 854 records for eligibility of effect size calculation and excluded $36 \%$ of these records mainly due to a missing control group (59\% of ineligible records) or missing essential values for effect size calculation (21\%; Supporting Information Figure S1). Finally, a total of 122 studies containing 549 effect sizes were included in our meta-analysis wherein $35 \%$ effect sizes originated from unpublished sources (Table 2). The vast majority of the analysed effect sizes originated from Europe or North America (94\%; Supporting Information Figure S6) and the data contained information about 7,829 tagged and 17,834 control individuals of 69 species from 27 families and 7 orders (Supporting Information Table S7).

We found a weak overall negative effect (Hedges' g: $-0.2 ; 95 \%$ $\mathrm{Crl}-0.29,-0.11 ; p<0.001)$ only on apparent survival in the model not controlled for phylogeny (model 1). Although we found no statistically significant overall tagging effects in any trait category when controlling for phylogenetic relatedness, the estimates were 
FIGURE 1 Overall effects of geolocators in the four trait categories, circles give means, horizontal lines represent $95 \% \mathrm{Crl}$. Filled symbols present the phylogenetically controlled overall effects, open symbols give the value from null models not accounting for phylogeny. $N$ presents the number of effect sizes analysed. For the detailed description of the trait categories, see Methods and Supporting Information Table S2

TAB LE 3 Summary of the full trait model ( $n=281$; model 3 ) and the ecological model ( $n=426$; model 4 ) of the geolocator effects on apparent survival. Levels contrasted against the reference level are given in parentheses

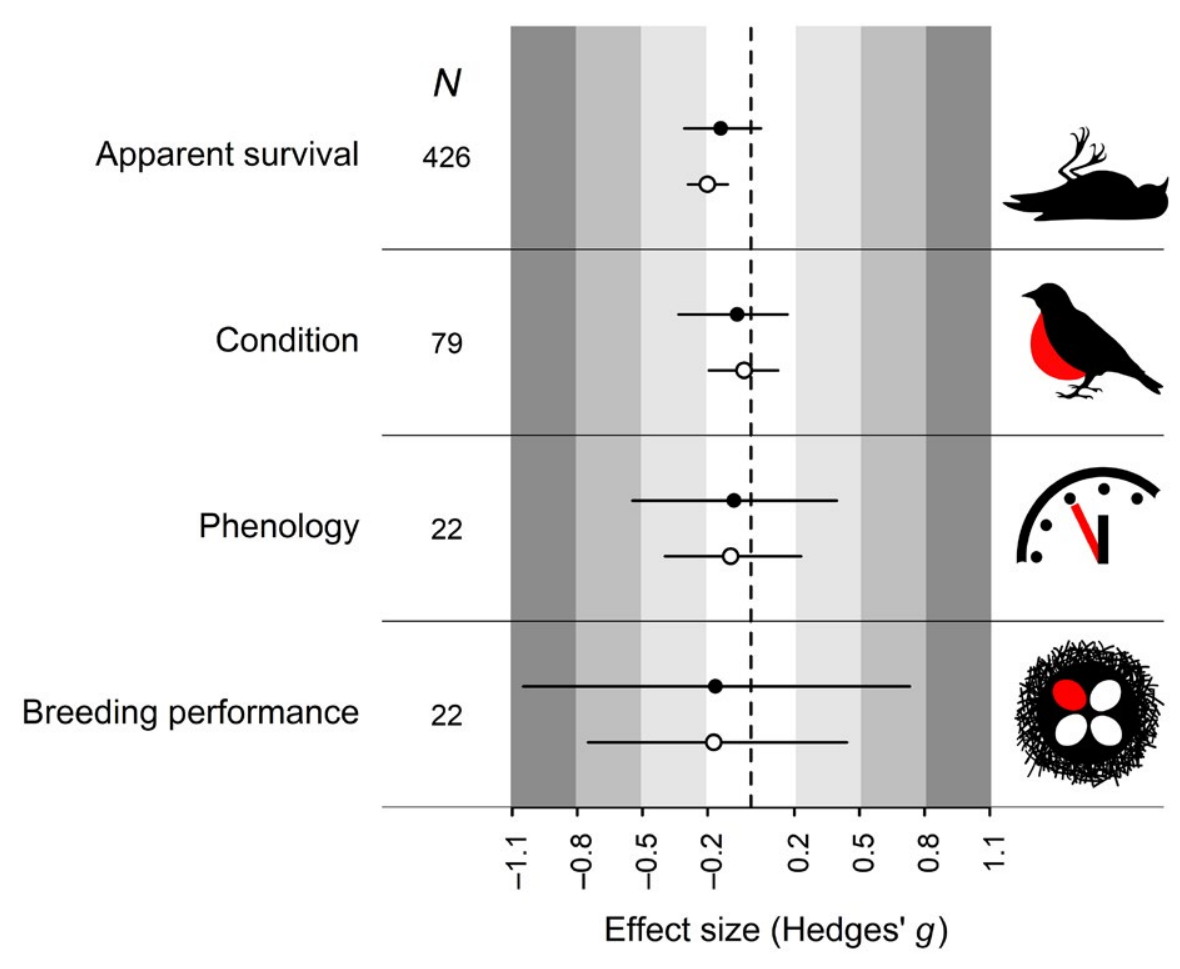

\begin{tabular}{|llllll|}
\hline Trait & Estimate & SE & $Z$ & $95 \% \mathrm{Cl}$ & $p$ \\
\hline Full trait model & & & & & \\
\hline Intercept & -0.25 & 0.10 & -2.59 & $(-0.44 ;-0.06)$ & 0.010 \\
\hline Published (published) & 0.14 & 0.10 & 1.39 & $(-0.06 ; 0.34)$ & 0.164 \\
\hline Control type (matched) & -0.05 & 0.09 & -0.61 & $(-0.23 ; 0.12)$ & 0.542 \\
\hline $\begin{array}{l}\text { Foraging strategy } \\
\text { (aerial) }\end{array}$ & -0.09 & 0.14 & -0.61 & $(-0.36 ; 0.19)$ & 0.540 \\
\hline Sex (males) & & & & & \\
\hline Relative load & -0.07 & 0.05 & -1.30 & $(-0.17 ; 0.03)$ & 0.192 \\
\hline Stalk/pipe length & -0.12 & 0.05 & -2.36 & $(-0.23 ;-0.02)$ & 0.018 \\
\hline Material elasticity & 0.07 & 0.04 & 1.77 & $(-0.01 ; 0.15)$ & 0.077 \\
\hline (non-elastic) & 0.19 & 0.08 & 2.21 & $(0.03 ; 0.35)$ & 0.026 \\
\hline Foraging strategy & -0.10 & 0.07 & -1.40 & $(-0.25 ; 0.04)$ & 0.161 \\
\hline (aerial) $\times$ stalk length & & & & & \\
\hline Ecological model & & & & & 0.001 \\
\hline Intercept & -0.26 & 0.08 & -3.20 & $(-0.42 ;-0.10)$ & 0.026 \\
\hline PC1 & 0.06 & 0.03 & 2.32 & $(0.01 ; 0.11)$ & 0.026 \\
\hline PC2 & 0.02 & 0.03 & 0.47 & $(-0.05 ; 0.08)$ & 0.638 \\
\hline Dense habitat (yes) & 0.03 & 0.13 & 0.21 & $(-0.22 ; 0.27)$ & 0.834 \\
\hline Nest type (open) & 0.14 & 0.11 & 1.27 & $(-0.08 ; 0.36)$ & 0.205 \\
\hline
\end{tabular}

similar to those not controlled for phylogeny (model 2, Figure 1). The phylogenetic signal $\left(H^{2}=59 \%\right)$ was statistically significant only for apparent survival, suggesting that closely related species have more similar response to tagging than less related species, but the variances explained by phylogeny and species were very low for all models (Supporting Information Table S8).

The full trait model of apparent survival revealed that tagging effects were stronger with increasing load on tagged individuals and that geolocators with elastic harnesses affected birds more negatively than geolocators with non-elastic harnesses (Table 3 , Figure 2). However, we found no statistically significant effect on apparent survival for control group type, sex, stalk length, foraging strategy or the interaction between stalk length and foraging strategy (model 3, Table 3). The ecological model suggested a relationship of apparent survival with the PC1, with negative effects being stronger with decreasing body, egg and clutch mass (model 4, Table 3). 


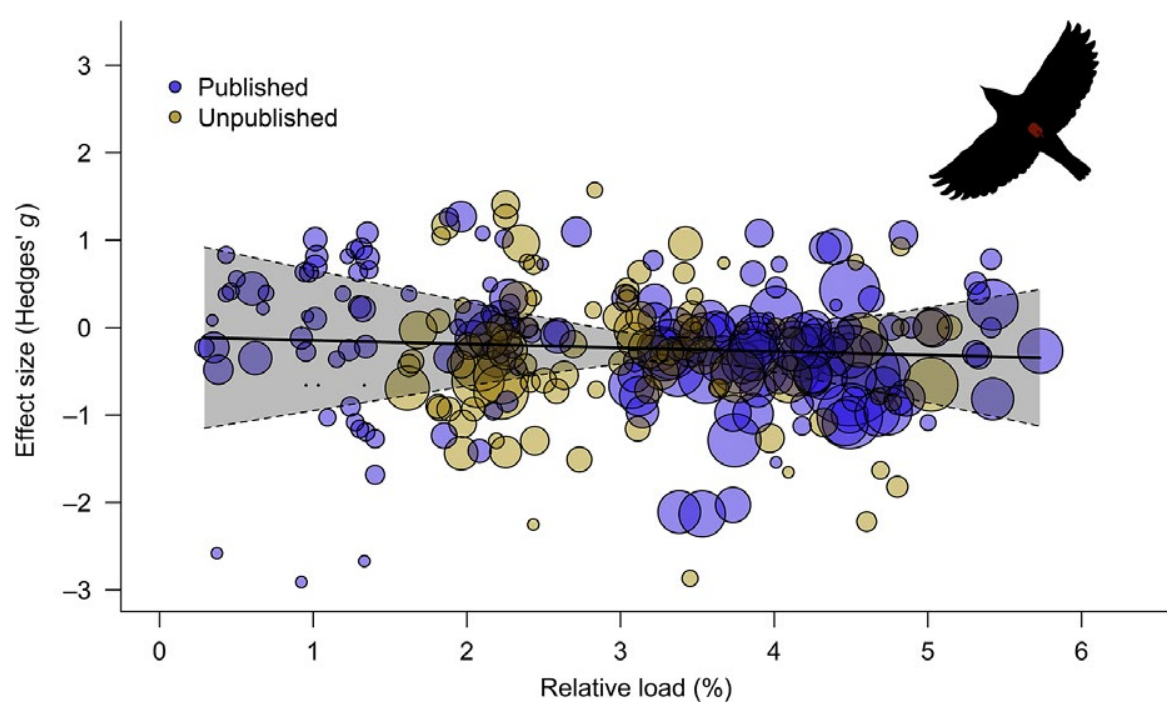

FIGURE 2 Relationship between relative load and the effect of geolocator deployment on the apparent survival of tagged birds. Size of the circles reflects the precision (1/mean-adjusted SE) of the effect sizes, the shaded area and dashed lines depict the $95 \% \mathrm{Cl}$ of the regression
The full trait model explained $21.1 \%$ and the ecological model $11.8 \%$ of the between-study variance.

We did not find any evidence for publication bias in any of the trait categories, either visually in the funnel plots (Supporting Information Figure S5), or using Egger's regression tests (Table 2). Moreover, there were no statistically significant differences in tagging effects between published and unpublished studies (model 5, Supporting Information Table S9). The geolocator-tagged birds were on average 3.8\% heavier than control individuals prior to the geolocator deployment and marking (LMM: estimate $0.008 \pm 0.003, t=2.47, p=0.014$ ).

\section{5 | DISCUSSION}

Geolocator deployment has a potential to reduce a bird's apparent survival, condition, breeding performance or may delay events of the annual cycle leading to biases in movement data. By conducting a quantitative review of published studies deploying geolocators on small bird species and incorporating unpublished data, we revealed only a weak overall effect of geolocators on apparent survival of tagged birds while we found no clear overall effect on condition, phenology and breeding performance. Moreover, we found no statistically significant effects of tagging in any of trait categories when accounting for phylogenetic relationships. Tagging effects on apparent survival were stronger with a higher relative load, when the geolocators were attached with elastic harnesses and in small-bodied species.

\section{1 | Overall tag effects}

A negative overall effect of geolocator tagging on apparent survival found in this study seems to be prevalent across previous comparative studies of tagging effects (Barron et al., 2010; Bodey et al., 2018a, 2018b; Costantini \& Møller, 2013; Trefry, Diamond, \& Jesson, 2012; Weiser et al., 2016). However, unlike previous comparative (Barron et al., 2010; Bodey et al., 2018a, 2018b) and primary studies (e.g. Adams et al., 2009; Arlt et al., 2013; Snijders et al., 2017), we found no overall negative effects of tagging on variables associated with breeding performance in our analysis. We also did not find evidence for overall effects of tagging on body condition and phenology, which was consistent with equivocal results of previous studies: Some found reduced body condition (Adams et al., 2009; Elliott et al., 2012) or delayed timing of annual cycle events (Arlt et al., 2013; Scandolara et al., 2014), while others found no evidence for tagging effects on these traits (Bell et al., 2017; Fairhurst et al., 2015; Peterson et al., 2015; van Wijk et al., 2015).

Tagged individuals that returned to the study site are potentially in better condition than the tagged individuals that did not returnthis potentially contributes to the weak tagging effects on condition, phenology and breeding performance. However, the lack of effect we found on phenology and breeding performance could also be an artefact of the small sample sizes, as collecting these data is probably more challenging in small avian species, which are more difficult to re-sight and recapture and have shorter life spans than the relatively heavier species included in the previous studies. Similarly, effects of tagging on condition could be underestimated in our analysis due to the initial differences we found between the body mass of tagged and control birds. Additionally, the intra-annual body mass changes could be biased in studies where timing of geolocator deployment and geolocator recovery differs. Unfortunately, the timing of captures and recaptures was rarely reported and could not be analysed in our study. Overall, the weak effects of tagging we found support several primary studies (e.g. Bell et al., 2017; Fairhurst et al., 2015; Peterson et al., 2015; van Wijk et al., 2015), indicating that geolocator tagging is both ethical and provides credible information on bird movements. On the other hand, care should be taken as the tagging effect may be specific to populations or species. For example, Weiser et al. (2016) found a negligible overall effect but significant reduction of return rates in the smallest species in their meta-analysis. The negative effect of geolocators can also vary between years (Bell et al., 2017; Scandolara et al., 2014), or be induced by occasional bad weather conditions (Snijders et al., 2017), or food shortages (Saraux et al., 2011; Wilson, Sala, Gómez-Laich, Ciancio, \& Quintana, 2015). 


\section{2 | Inferring unbiased overall effect sizes}

We minimized publication bias in our estimates of overall effects by including substantial amount of unpublished results (192 records of 38 species) and contacting authors of published studies for additional data. Still, some of these studies might get published in the future despite the delay between our data collation and the final analysis. We did not find any evidence that tagging effects differed between published and unpublished studies, suggesting that the tagging effect may not be a critical consideration for publishing a study.

Moreover, we found no support for stronger tag effects in studies with matched control individuals compared to studies with less strict control treatments. However, this result is potentially confounded by the fact that tagged birds were on average larger and in potentially better condition than control birds, which would underestimate the negative effects of tagging. We thus suggest establishing carefully matched control groups in all future studies to enable a more reliable estimation of tagging effects. Such a control group should include the following: (a) randomly selected individuals of the same species, sex and age class; (b) individuals caught at the same time of the season and year; (c) at the same time of the day; (d) of similar size and condition as tagged individuals; and (e) exclude nonterritorial birds or individuals passing through the site.

\section{3 | Influence of relative load and species' life histories}

Our results support the current evidence (Bodey et al., 2018a, 2018b; Weiser et al., 2016) for reduced apparent survival in studies with a relatively higher tag load on treated individuals. Moreover, we found an increasing negative effect in studies tagging smaller species with smaller eggs and clutch masses. The lower body mass in these species is likely accompanied with a higher relative tag load due to technical constraints of lower tag weights. Although recent miniaturization has led to the development of smaller tags, these tags have been predominantly applied to smaller species instead of reducing tag load in larger species (Portugal \& White, 2018). The various relative loads used without observed tagging effects (e.g. Bell et al., 2017; Peterson et al., 2015; van Wijk et al., 2015) indicate the absence of a generally applicable rule for all small bird species (Schacter \& Jones, 2017), and we thus recommend the use of reasonably small tags despite potential disadvantages (e.g. reduced battery life span or light sensor quality).

\section{4 | Harness material}

Contrary to our prediction, we found higher apparent survival in birds tagged with harnesses made of non-elastic materials. Non-elastic harnesses are usually individually adjusted on each individual, whereas elastic harnesses are often prepared before attachment to fit the expected body size of the tagged individuals according to allometric equations (e.g. NaefDaenzer, 2007). As pre-sized elastic harnesses cannot match perfectly the size of every captured individual, they may be in the end more frequently tightly fitted as some researches might tend to tag larger individuals or avoid too loose harnesses to prevent geolocator loss. Non-elastic harnesses may also be more frequently looser than elastic harnesses as researchers try to reduce the possibility of non-elastic harness getting tight when birds accumulate fat. Tight harnesses significantly reduced the return rates in whinchat (Saxicola rubetra; Blackburn et al., 2016), and it may be difficult to register whether elastic harnesses are restricting physical movement of birds when deploying tags. In contrast, non-elastic harnesses, which are more commonly tailored according to the actual size, are often made sufficiently loose to account for body mass changes in each individual. Prepared elastic harnesses are usually used to reduce the handling time during the geolocator deployment (Streby et al., 2015) but this advantage may be outweighed by the reduced apparent survival of geolocators with tied elastic harnesses. We thus suggest to consider stress during geolocator deployment together with the potentially reduced apparent survival and the risk of tag loss when choosing harness material.

\section{5 | Variables without statistically significant impact on tagging effect}

Migratory distance did not affect the magnitude of the effect sizes, contrasting with some previous findings (Bodey et al., 2018a, 2018b; Costantini \& Møller, 2013). However, none of these studies used population-specific distances travelled; instead, they used latitudinal spans between ranges of occurrence (Costantini \& Møller, 2013) or travelled distance categorized into three distances groups (Bodey et al., 2018a, 2018b). These types of distance measurements could greatly affect the results especially in species that migrate mainly in an east-west direction (Lislevand et al., 2015; Stach, Kullberg, Jakobsson, Ström, \& Fransson, 2016) or in species whose populations largely differ in their travel distances (Bairlein et al., 2012; Schmaljohann, Buchmann, Fox, \& Bairlein, 2012). Moreover, light-level geolocators were most frequently deployed to the long-distance migrants in our study and the result can be thus applicable to these species only.

Additionally, we found no overall effect of species' foraging strategy, contrary to the strong overall negative effect found for aerial foraging species (Costantini \& Møller, 2013). Despite the tag shape altering the drag and thus energy expenditure during flight (Bowlin et al., 2010; Pennycuick et al., 2012), apparent survival tended to be better in individuals fitted with stalked geolocators and we found no interaction between stalk length and foraging strategy on the tagging effect size. Geolocators with longer stalks have been more frequently used in heavier birds with low relative load where the expected tag effect is weak. Moreover, previous results of strong negative effects in aerial foragers led to a preferential use of stalkless geolocators in these species and probably minimized the tagging effect in this foraging guild (Morganti et al., 2018; Scandolara et al., 2014). However, the evidence for the negative effects in non-aerial foragers is low as there is only one field study focusing on stalk length effects on the return rates (Blackburn et al., 2016).

\section{6 | Future considerations}

Future studies evaluating the use of geolocators on birds should focus on assessing interannual differences in tagging effects, effects 
of varying relative loads, different stalk lengths or different attachment methods to minimize the negative effects of tagging. We also suggest to focus on the impact of various movement strategies such as fattening and moulting schedules on the tagging effect. All future studies should carefully set matched controls and transparently report on tagging effects. Finally, our results encourage use of geolocators on small bird species but the ethical and scientific benefits should always be considered.

\section{ACKNOWLEDGEMENTS}

We thank James W. Fox (Migrate Technology), the Swiss Ornithological Institute, Biotrack/Lotek employees for circulating the call for sharing the unpublished study results among their customers and Rien van Wijk for sharing our inquiry for unpublished data among the Migrant Landbird Study Group members. We are grateful to Carlos Camacho, Vladimir G. Grinkov, Helene M. Lampe, Ken Otter, Jaime Potti, Milica Požgayová, Scott M. Ramsay and Helmut Sternberg for providing unpublished data and to Marie Hánová for extracting part of the species-specific life-history data. We thank Martin Sládeček, anonymous reviewers and editors for valuable comments on the earlier version of the manuscript and Adéla Stupková for the graphics. The fieldwork in Greenland and Russia (Yamal Peninsula) was supported by the RFBR through grant Arctic-18-05-60261, Yamal-LNG company (Sabetta) and the French Polar Institute (IPEV, program 1036 "Interactions"). D.K. was supported by the Russian Science Foundation grant (project no. 17-14-01147) and by a Leverhulme Trust research grant to Richard Holland (RPG-2013288). The study was funded by the Czech Science Foundation (project no. 13-06451S) and by the Institutional Research Plan (RVO: 68081766). We are grateful to the funders, supporters and researchers of the many studies included herein. Any use of trade, firm or product names is for descriptive purposes only and does not imply endorsement by the U.S. Government.

\section{AUTHORS' CONTRIBUTIONS}

V.Br., J.K. and P.P. conceived the idea and designed the methodology. V.Br. reviewed the literature and collected data. J.K. and P.P. checked the data extracted for analysis. V.Br. and P.P. analysed the data. V.Br. led the writing of the manuscript with significant contributions from J.K. and P.P. M.B., S.H., D.H., M.K., J.O. and E.W. contributed with unpublished data and their comments and suggestions significantly improved the manuscript. P.A., J.A., D.A., S.B., D.B., E.B., V.Be., C.B., S.B., M.Br., B.C., D.C., N.C., J.C., V.C., T.E., K.F., O.G., M.G., M.H., C.H., F.J., J.J., T.K., D.K., M.L., T.L., S.L., C.L., K.M., P.Mar., S.M., P.Mat., C.M., B.M., J.M., R.Ne., A.N., R.No., T.P., V.P., N.P., M.P., J.R., C.R., A.R., C.S., N.S., M.T., D.T., H.O., A.W., H.W., J.W., K.W. and B.W. contributed unpublished data and critically revised the manuscript. All authors gave final approval for publication.

\section{DATA ACCESSIBILITY}

Data described in this article are available at https://doi.org/10.5281/ zenodo.1886530 (Brlík et al., 2019).

\section{ORCID}

Vojtěch Brlík (iD https://orcid.org/0000-0002-7902-8123 Jaroslav Koleček iD https://orcid.org/0000-0003-1069-6593 Malcolm Burgess iD https://orcid.org/0000-0003-1288-1231 Steffen Hahn (iD https://orcid.org/0000-0002-4924-495X Miloš Krist iD https://orcid.org/0000-0002-6183-686X Janne Ouwehand (iD https://orcid.org/0000-0003-2573-6287 Emily L. Weiser (iD https://orcid.org/0000-0003-1598-659X Peter Adamík (ID https://orcid.org/0000-0003-1566-1234 José A. Alves iD https://orcid.org/0000-0001-7182-0936 Debora Arlt iD https://orcid.org/0000-0003-0874-4250 Sanja Barišić iD https://orcid.org/0000-0003-3472-3285 Eduardo J. Belda (D) https://orcid.org/0000-0003-1995-1271 Christiaan Both iD https://orcid.org/0000-0001-7099-9831 Martins Briedis (iD https://orcid.org/0000-0002-9434-9056 Davor Ćiković iD https://orcid.org/0000-0002-3234-0574 Nathan W. Cooper (ID https://orcid.org/0000-0002-4667-1542 Joana S. Costa iD https://orcid.org/0000-0002-1532-8936 Tamara Emmenegger (iD https://orcid.org/0000-0002-2839-6129 Olivier Gilg iD https://orcid.org/0000-0002-9083-4492 Michael T. Hallworth iD https://orcid.org/0000-0002-6385-3815 Chris Hewson (iD https://orcid.org/0000-0002-8493-5203 Frédéric Jiguet iD https://orcid.org/0000-0002-0606-7332 Dmitry Kishkinev iD https://orcid.org/0000-0002-2619-1197 Terje Lislevand (iD https://orcid.org/0000-0003-1281-7061 Simeon Lisovski iD https://orcid.org/0000-0002-6399-0035 Kent P. McFarland iD https://orcid.org/0000-0001-7809-5503 Piotr Matyjasiak iD https://orcid.org/0000-0003-0384-2935 Christoph M. Meier (D) https://orcid.org/0000-0001-9584-2339 Tomas Pärt (iD https://orcid.org/0000-0001-7388-6672 Markus Piha iD https://orcid.org/0000-0002-8482-6162 Jeroen Reneerkens iD https://orcid.org/0000-0003-0674-8143 Natalia Sokolova (iD https://orcid.org/0000-0002-6692-4375 Arndt H. J. Wellbrock iD https://orcid.org/0000-0001-9929-7091 Klaudia Witte iD https://orcid.org/0000-0002-2812-9936 Bradley K. Woodworth (iD https://orcid.org/0000-0002-4528-8250 Petr Procházka iD https://orcid.org/0000-0001-9385-4547 


\section{REFERENCES}

Adams, J., Scott, D., McKechnie, S., Blackwell, G., Shaffer, S. A., \& Moller, H. (2009). Effects of geolocation archival tags on reproduction and adult body mass of sooty shearwaters (Puffinus griseus). New Zealand Journal of Zoology, 36, 355-366. https://doi. org/10.1080/03014220909510160

Arlt, D., Low, M., \& Pärt, T. (2013). Effect of geolocators on migration and subsequent breeding performance of a long-distance passerine migrant. PLoS ONE, 8, e82316. https://doi.org/10.1371/journal.pone.0082316

Bairlein, F., Norris, D. R., Nagel, R., Bulte, M., Voigt, C. C., Fox, J., ... Schmalljohann, H. (2012). Cross-hemisphere migration of a $25 \mathrm{~g}$ songbird. Biology Letters, 8, 505-507. https://doi.org/10.1098/rsbl.2011.1223

Barron, D. G., Brawn, J. D., \& Weatherhead, P. J. (2010). Metaanalysis of transmitter effects on avian behaviour and ecology. Methods in Ecology and Evolution, 1, 180-187. https://doi. org/10.1111/j.2041-210X.2010.00013.x

Bell, S. C., Harouchi, M. E. L., Hewson, C. M., \& Burgess, M. D. (2017). No short- or long-term effects of geolocator attachment detected in Pied Flycatchers Ficedula hypoleuca. Ibis, 159, 734-743. https://doi. org/10.1111/ibi.12493

Blackburn, E., Burgess, M., Freeman, B., Risely, A., Izang, A., Ivande, S., ... Cresswell, W. (2016). An experimental evaluation of the effects of geolocator design and attachment method on between-year survival on Whinchats Saxicola rubetra. Journal of Avian Biology, 47, 530-539. https://doi.org/10.1111/jav.00871

Bodey, T. W., Cleasby, I. R., Bell, F., Parr, N., Schultz, A., Votier, S. C., \& Bearhop, S. (2018a). A phylogenetically controlled metaanalysis of biologging device effects on birds: Deleterious effects and a call for more standardized reporting of study data. Methods in Ecology and Evolution, 9, 946-955. https://doi. org/10.1111/2041-210X.12934

Bodey, T. W., Cleasby, I. R., Bell, F., Parr, N., Schultz, A., Votier, S. C., \& Bearhop, S. (2018b). Data from: A phylogenetically controlled metaanalysis of biologging device effects on birds: Deleterious effects and a call for more standardized reporting of study data. Dryad Digital Depository. https://doi.org/10.5061/dryad.Orp52

Borenstein, M., Hedges, L. V., Higgins, J. P. T., \& Rothstein, H. R. (2009). Introduction to meta-analysis. Chichester, UK: John Wiley \& Sons.

Bowlin, M. S., Henningsson, P., Muijres, F. T., Vleugels, R. H. E., Liechti, F., \& Hedenström, A. (2010). The effects of geolocator drag and weight on the flight ranges of small migrants. Methods in Ecology and Evolution, 1, 398-402. https://doi. org/10.1111/j.2041-210X.2010.00043.x

Bridge, E. S., Kelly, J. F., Contina, A., Gabrielson, R. M., MacCurdy, R. B., \& Winkler, D. W. (2013). Advances in tracking small migratory birds: A technical review of light-level geolocation. Journal of Field Ornithology, 84, 121-137. https://doi.org/10.1111/jofo.12011

Brlík, V., Koleček, J., Burgess, M. D., Hahn, S., Humple, D., Krist, M., ... Procházka, P. (2019). Weak effects of geolocators on small birds: A meta-analysis controlled for phylogeny and potential publication bias. Zenodo. https://doi.org/10.5281/zenodo.1886530

Caccamise, D. F., \& Hedin, R. S. (1985). An aerodynamic basis for selecting transmitter loads in birds. The Wilson Bulletin, 97, 306-318.

Costantini, D., \& Møller, A. P. (2013). A meta-analysis of the effects of geolocator application on birds. Current Zoology, 59, 697-706. https:// doi.org/10.1093/czoolo/59.6.697

Cramp, S., \& Perrins, C. M. (1977-1994). The birds of the Western Palearctic. Volumes 1-9. Oxford, UK: Oxford University Press.

Del Re, A. C. (2013). compute.es: Compute effect sizes. R package version 0.2-2. Retrieved from https://cran.r-project.org/web/packages/ compute.es/index.html

Doncaster, C. P., \& Spake, R. (2018). Correction for bias in meta-analysis of little-replicated studies. Methods in Ecology and Evolution, 9, 634644. https://doi.org/10.1111/2041-210X.12927
Elliott, K. H., McFarlane, L., Burke, C. M., Hedd, A., Montevecchi, W. A., \& Anderson, W. G. (2012). Year-long deployments of small geolocators increase corticosterone levels in murres. Marine Ecology Progress Series, 466, 1-7. https://doi.org/10.3354/meps09975

Fairhurst, G. D., Berzins, L. L., David, W., Laughlin, A. J., Romano, A., Romano, M., ... Clark, R. G. (2015). Assessing costs of carrying geolocators using feather corticosterone in two species of aerial insectivore. Royal Society Open Science, 2, 150004. https://doi.org/10.1098/ rsos. 150004

Guillerme, T., \& Healy, K. (2017). mulTree: Performs MCMCglmm on multiple phylogenetic trees. R package version 1.3.1. Retrieved from https:// github.com/TGuillerme/mulTree

Hackett, S., Kimball, R., Reddy, S., Bowie, R., Braun, E., Braun, M., ... Yuri, T. (2008). A phylogenomic study of birds reveals their evolutionary history. Science, 320, 1763-1768. https://doi.org/10.1126/ science.1157704

Hadfield, J. D. (2010). MCMC methods for multi-response generalized linear mixed models: The MCMCgImm R package. Journal of Statistical Software, 33, 1-22.

Hadfield, J. D., \& Nakagawa, S. (2010). General quantitative genetic methods for comparative biology: Phylogenies, taxonomies and multi-trait models for continuous and categorical characters. Journal of Evolutionary Biology, 23, 494-508. https://doi. org/10.1111/j.1420-9101.2009.01915.x

Jetz, W., Thomas, G. H., Joy, J. B., Hartmann, K., \& Mooers, A. O. (2012). The global diversity of birds in space and time. Nature, 491, 444-448. https://doi.org/10.1038/nature11631

Jewell, Z. (2013). Effect of monitoring technique on quality of conservation science. Conservation Biology, 27(3), 501-508. https://doi. org/10.1111/cobi.12066

Koricheva, J., Gurevitch, J., \& Mengersen, K. (2013). Handbook of meta-analysis in ecology and evolution. Princeton, NJ: Princeton University Press.

Lislevand, T., Chutný, B., Byrkjedal, I., Pavel, `., Briedis, M., Adamík, P., \& Hahn, S. (2015). Red-spotted Bluethroats Luscinia s. svecica migrate along the Indo-European flyway: A geolocator study. Bird Study, 62, 508-515. https://doi.org/10.1080/00063657.2015.1077781

López-López, J. A., Marín-Martínez, F., Sánchez-Meca, J., Van den Noortgate, W., \& Viechtbauer, W. (2014). Estimation of the predictive power of the model in mixed-effects meta-regression: A simulation study. British Journal of Mathematical and Statistical Psychology, 67, 30-48. https://doi.org/10.1111/bmsp.12002

McKinnon, E. A., \& Love, O. P. (2018). Ten years tracking the migrations of small landbirds: Lessons learned in the golden age of bio-logging. The Auk, 135, 834-856. https://doi.org/10.1642/AUK-17-202.1

Morganti, M., Rubolini, D., Åkesson, S., Bermejo, A., de la Puente, J., Lardelli, R., ... Ambrosini, R. (2018). Effect of light-level geolocators on apparent survival of two highly aerial swift species. Journal of Avian Biology, 49, jav-01521. https://doi.org/10.1111/jav.01521

Naef-Daenzer, B. (2007). An allometric function to fit leg-loop harnesses to terrestrial birds. Journal of Avian Biology, 38, 404-407. https://doi. org/10.1111/j.2007.0908-8857.03863.x

Nakagawa, S., \& Santos, E. S. A. (2012). Methodological issues and advances in biological meta-analysis. Evolutionary Ecology, 26, 12531274. https://doi.org/10.1007/s10682-012-9555-5

Pakanen, V. M., Rönkä, N., Thomson, R. L., \& Koivula, K. (2015). No strong effects of leg-flagged geolocators on return rates or reproduction of a small long-distance migratory shorebird. Ornis Fennica, 92, 101-111.

Patchett, R., Finch, T., \& Cresswell, W. (2018). Population consequences of migratory variability differ between flyways. Current Biology, 28, R340-R341. https://doi.org/10.1016/j.cub.2018.03.018

Pennycuick, C. J., Fast, P. L. F., Ballerstädt, N., \& Rattenborg, N. (2012). The effect of an external transmitter on the drag coefficient of a bird's body, and hence on migration range, and energy reserves after migration. Journal of Ornithology, 153, 633-644. https://doi.org/10.1007/ sl0336-011-0781-3 
Peterson, S. M., Streby, H. M., Kramer, G. R., Lehman, J. A., Buehler, D. A., \& Andersen, D. E. (2015). Geolocators on Golden-winged Warblers do not affect migratory ecology. The Condor, 117, 256-261. https:// doi.org/10.1650/CONDOR-14-200.1

Portugal, S. J., \& White, C. R. (2018). Miniaturisation of biologgers is not alleviating the 5\% rule. Methods in Ecology and Evolution, 9, 16621666. https://doi.org/10.1111/2041-210X.13013

R Core Team. (2018). R: A language and environment for statistical computing. Vienna, Austria: R foundation for Statistical Computing. Retrieved from https://www.R-project.org/

Rodewald, P. (2015). The birds of North America. Ithaca, NY: Cornell Laboratory of Ornithology. Retrieved from https://birdsna.org

Sánchez-Tójar, A., Nakagawa, S., Sánchez-Fortún, M., Martin, D. A. Ramani, S., Girndt, A., ... Schroeder, J. (2018). Meta-analysis challenges a textbook example of status signalling and demonstrates publication bias. eLife, 7, e37385. https://doi.org/10.7554/eLife. 37385

Saraux, C., Le Bohec, C., Durant, J. M., Viblanc, V. A., Gauthier-Clerc, M., Beaune, D., ... Le Maho, Y. (2011). Reliability of flipper-banded penguins as indicators of climate change. Nature, 469, 203-206. https:// doi.org/10.1038/nature09630

Scandolara, C., Rubolini, D., Ambrosini, R., Caprioli, M., Hahn, S., Liechti, F., ... Saino, N. (2014). Impact of miniaturized geolocators on barn swallow Hirundo rustica fitness traits. Journal of Avian Biology, 45, 417-423. https://doi.org/10.1111/jav.00412

Schacter, C. R., \& Jones, I. L. (2017). Effects of geolocation tracking devices on behavior, reproductive success, and return rate of Aethia auklets: An evaluation of tag mass guidelines. The Wilson Journal of Ornithology, 129, 459-468. https://doi.org/10.1676/16-084.1

Schmaljohann, H., Buchmann, M., Fox, J. W., \& Bairlein, F. (2012). Tracking migration routes and the annual cycle of a trans-Sahara songbird migrant. Behavioral Ecology and Sociobiology, 66, 915-922. https://doi. org/10.1007/s00265-012-1340-5

Schönwetter, M. (1960-1992). Handbuch der oologie. Berlin, Germany: Akademie Verlag.

Schwarzer, G., Carpenter, J. R., \& Rücker, G. (2014). Meta-analysis with R. London, UK: Springer.

Snijders, L., Nieuwe Weme, L. E., De Goede, P., Savage, J. L., Van Oers, K., \& Naguib, M. (2017). Context-dependent effects of radio transmitter attachment on a small passerine. Journal of Avian Biology, 48, 650-659. https://doi.org/10.1111/jav.01148

Stach, R., Kullberg, C., Jakobsson, S., Ström, K., \& Fransson, T. (2016). Migration routes and timing in a bird wintering in South Asia, the Common Rosefinch Carpodacus erythrinus. Journal of Ornithology, 157, 756-767. https://doi.org/10.1007/s10336-016-1329-3

Stanley, C. Q., MacPherson, M., Fraser, K. C., McKinnon, E. A., \& Stutchbury, B. J. M. (2012). Repeat tracking of individual songbirds reveals consistent migration timing but flexibility in route. PLOS ONE, 7, e40688. https://doi.org/10.1371/journal.pone.0040688

Streby, H. M., McAllister, T. L., Peterson, S. M., Kramer, G. R., Lehman, J. A., \& Andersen, D. E. (2015). Minimizing marker mass and handling time when attaching radio-transmitters and geolocators to small songbirds. The Condor, 117, 249-255. https://doi.org/10.1650/ CONDOR-14-182.1

Sweeting, M. J., Sutton, A. J., \& Lambert, P. C. (2004). What to add to nothing? Use and avoidance of continuity corrections in metaanalysis of sparse data. Statistics in Medicine, 23, 1351-1375. https:// doi.org/10.1002/sim.1761

Trefry, S. A., Diamond, A. W., \& Jesson, L. K. (2012). Wing marker woes: A case study and meta-analysis of the impacts of wing and patagial tags. Journal of Ornithology, 154, 1-11. https://doi.org/10.1007/ s10336-012-0862-y

van Wijk, R. E., Souchay, G., Jenni-Eiermann, S., Bauer, S., \& Schaub, M. (2015). No detectable effects of lightweight geolocators on a Palaearctic-African long-distance migrant. Journal of Ornithology, 157, 255-264. https://doi.org/10.1007/s10336-015-1274-6
Viechtbauer, W. (2010). Conducting meta-analyses in R with the metafor package. Journal Of Statistical Software, 36, 1-48.

Weimerskirch, H., Bonadonna, F., Bailleul, F., Mabille, G., Dell'Omo, G., \& Lipp, H.-P. (2002). GPS tracking of foraging albatrosses. Science, 295, 1259. https://doi.org/10.1126/science.1068034

Weiser, E. L., Lanctot, R. B., Brown, S. C., Alves, J. A., Battley, P. F., Bentzen, R., ... Sandercock, B. K. (2016). Effects of geolocators on hatching success, return rates, breeding movements, and change in body mass in 16 species of Arctic-breeding shorebirds. Movement Ecology, 4, 12. https://doi.org/10.1186/s40462-016-0077-6

Wilson, R. P., \& McMahon, C. R. (2006). Measuring devices on wild animals: What constitutes acceptable practice? Frontiers in Ecology and the Environment, 4, 147-154. https://doi.org/10.1890/15409295(2006) 004[0147:MDOWAW]2.0.CO;2

Wilson, R. P., Sala, J. E., Gómez-Laich, A., Ciancio, J., \& Quintana, F. (2015). Pushed to the limit: Food abundance determines taginduced harm in penguins. Animal Welfare, 24, 37-44. https://doi org/10.7120/09627286.24.1.037

\section{PUBLISHED DATA SOURCES}

Alonso, D., Arizaga, J., Meier, C. M., \& Liechti, F. (2017). Light-level geolocators confirm resident status of a Southern European Common Crossbill population. Journal of Ornithology, 158, 75-81. https://doi.org/10.1007/ s10336-016-1388-5

Arbeiter, S., Schulze, M., Todte, I., \& Hahn, S. (2012). Das Zugverhalten und die Ausbreitung von in Sachsen-Anhalt brütenden Bienenfressern (Merops apiaster). Berichte der Vogelwarte Hiddensee, 21, 33-41.

Arlt, D., Low, M., \& Pärt, T. (2013). Effect of geolocators on migration and subsequent breeding performance of a long-distance passerine migrant. PLOS ONE, 8 e82316. https://doi.org/10.1371/journal.pone.0082316

Arlt, D., Olsson, P., Fox, J. W., Low, M., \& Pärt, T. (2015). Prolonged stopover duration characterises migration strategy and constraints of a long-distance migrant songbird. Animal Migration, 2, 47-62. https://doi.org/10.1515/ ami-2015-0002

Bächler, E., Hahn, S., Schaub, M., Arlettaz, R., Jenni, L., Fox, J. W., ... Liechti, F. (2010). Year-round tracking of small trans-Saharan migrants using light-level geolocators. PLoS ONE, 5, e9566. https://doi.org/10.1371/journal.pone.0009566

Bairlein, F., Norris, D. R., Nagel, R., Bulte, M., Voigt, C. C., Fox, J., ... Schmalljohann, H. (2012). Cross-hemisphere migration of a 25 g songbird. Biology Letters, 8 , 505-507. https://doi.org/10.1098/rsbl.2011.1223

Bell, S. C., Harouchi, M. E. L., Hewson, C. M., \& Burgess, M. D. (2017). No shortor long-term effects of geolocator attachment detected in Pied Flycatchers Ficedula hypoleuca. Ibis, 159, 734-743. https://doi.org/10.1111/ibi.12493

Blackburn, E., Burgess, M., Freeman, B., Risely, A., Izang, A., Ivande, S., ... Cresswell, W. (2016). An experimental evaluation of the effects of geolocator design and attachment method on between-year survival on Whinchats Saxicola rubetra. Journal of Avian Biology, 47, 530-539. https://doi.org/10.1111/jav.00871

Bravo, S. P., Cueto, V. R., \& Andre, C. (2017). Migratory timing, rate, routes and wintering areas of White-crested Elaenia (Elaenia albiceps chilensis), a key seed disperser for Patagonian forest regeneration. PLoS ONE, 12, e0170188. https:// doi.org/10.1371/journal.pone.0170188

Briedis, M., Beran, V., Hahn, S., \& Adamík, P. (2016). Annual cycle and migration strategies of a habitat specialist, the Tawny Pipit Anthus campestris, revealed by geolocators. Journal of Ornithology, 157, 619-626. https://doi.org/10.1007/ s10336-015-1313-3

Briedis, M., Hahn, S., Gustafsson, L., Henshaw, I., Träff, J., Král, M., \& Adamík, P. (2016). Breeding latitude leads to different temporal but not spatial organization of the annual cycle in a long-distance migrant. Journal of Avian Biology, 47, 743-748. https://doi.org/10.1111/jav.01002

Briedis, M., Träff, J., Hahn, S., llieva, M., Král, M., Peev, S., \& Adamík, P. (2016). Yearround spatiotemporal distribution of the enigmatic Semi-collared Flycatcher Ficedula semitorquata. Journal of Ornithology, 157, 895-900. https://doi. org/10.1007/s10336-016-1334-6

Brlík, V., Ilieva, M., Lisovski, S., Voigt, C. C., \& Procházka, P. (2018). First insights into the migration route and migratory connectivity of the Paddyfield Warbler using geolocator tagging and stable isotope analysis. Journal of Ornithology, 159, 879-882. https://doi.org/10.1007/s10336-018-1557-9

Callo, P. A., Morton, E. S., \& Stutchbury, B. J. M. (2013). Prolonged spring migration in the Red-eyed Vireo (Vireo olivaceus). The Auk, 130, 240-246. https://doi. org/10.1525/auk.2013.12213

Cooper, N. W., Hallworth, M. T., \& Marra, P. P. (2017). Light-level geolocation reveals wintering distribution, migration routes, and primary stopover locations of an endangered long-distance migratory songbird. Journal of Avian Biology, 48 209-2019. https://doi.org/10.1111/jav.01096

Cormier, R. L., Humple, D. L., Gardali, T., \& Seavy, N. E. (2013). Light-level geolocators reveal strong migratory connectivity and within-winter movements for a coastal California Swainson's thrush (Catharus ustulatus) population. The Auk, 130, 283-290. https://doi.org/10.1525/auk.2013.12228 
Cormier, R. L., Humple, D. L., Gardali, T., \& Seavy, N. E. (2016). Migratory connectivity of Golden-crowned Sparrows from two wintering regions in California. Animal Migration, 3, 48-56. https://doi.org/10.1515/ami-2016-0005

Cresswell, B., \& Edwards, D. (2013). Geolocators reveal wintering areas of European Nightjar (Caprimulgus europaeus). Bird Study, 60, 77-86. https://doi.org/10.108 $0 / 00063657.2012 .748714$

DeLuca, W. V., Woodworth, B. K., Rimmer, C. C., Marra, P. P., Taylor, P. D., McFarland K. P., ... Norris, D. R. (2015). Transoceanic migration by a $12 \mathrm{~g}$ songbird. Biology Letters, 11, 20141045. https://doi.org/10.1098/rsbl.2014.1045

Evens, R., Convay, G. J., Henderson, I. G., Creswell, W., Jiguet, F., Moussy, C., ... Artois, T. (2017). Migratory pathways, stopover zones and wintering destinations of Western European Nightjars Caprimulgus europaeus. Ibis, 159, 680-686. https://doi.org/10.1111/ijlh.12426

Fairhurst, G. D., Berzins, L. L., Bradley, D. W., Laughlin, A. J., Romano, A., Romano, M., .. Clark, R. G. (2015). Assessing costs of carrying geolocators using feather corticosterone in two species of aerial insectivore. Royal Society Open Science, 2, 150004 https://doi.org/10.1098/rsos.150004

Fairhurst, G. D., Berzins, L. L., Bradley, D. W., Laughlin, A. J., Romano, A., Romano, M., ... Clark, R. G. (2015). Data from: Assessing costs of carrying geolocators using feather corticosterone in two species of aerial insectivore. Dryad Digital Repository. https://doi.org/10.5061/dryad.sq184

Fraser, K. C., Cousens, B., Simmons, M., Nightingale, A., Cormier, L., Humple, D. L., \& Shave, A. C. (2018). Classic pattern of leapfrog migration in Sooty Fox Sparrow (Passerella iliaca unalaschcensis) is not supported by direct migration tracking of individual birds. Auk, 135, 572-582. https://doi.org/10.1642/ AUK-17-224.1

Fraser, K. C., Stutchbury, B. J. M., Silverio, C., Kramer, P. M., Barrow, J., Newstead, D., ... Tautin, J. (2012). Continent-wide tracking to determine migratory connectivity and tropical habitat associations of a declining aerial insectivore. Proceedings of the Royal Society B-Biological Sciences, 279, 4901-4906. https:// doi.org/10.1098/rspb.2012.2207

Gersten, A., \& Hahn, S. (2016). Timing of migration in Common Redstarts (Phoenicurus phoenicurus) in relation to the vegetation phenology at residence sites. Journal of Ornithology, 157, 1029-1036. https://doi.org/10.1007/ s10336-016-1359-x

Gómez, J., Michelson, C. I., Bradley, D. W., Ryan Norris, D., Berzins, L. L., Dawson, R. D., \& Clark, R. G. (2014). Effects of geolocators on reproductive performance and annual return rates of a migratory songbird. Journal of Ornithology, 155, 37-44. https://doi.org/10.1007/s10336-013-0984-x

Hallworth, M. T., Sillett, T. S., Van Wilgenburg, S. L., Hobson, K. A., \& Marra, P. P. (2015). Migratory connectivity of a neotropical migratory songbird revealed by archival light-level geolocators. Ecological Applications, 25, 336-347. https:// doi.org/10.1890/14-0195.1

Heckscher, C. M., Taylor, S. M., Fox, J. W., \& Afanasyev, V. (2011). Veery (Catharus fuscescens) wintering locations, migratory connectivity, and a revision of its winter range using geolocator technology. The Auk, 128, 531-542. https://doi. org/10.1525/auk.2011.10280

Horns, J., Buechley, E., Chynoweth, M., Aktay, L., Coban, E., Kırpık, M.,... Sekercioğlu, C. H. (2016). Geolocator tracking of great reed warbler (Acrocephalus arundinaceus) identifies key regions of importance to migratory wetland specialist throughout the Middle East and Sub-Saharan Africa. The Condor, 118, 835-849. https://doi.org/10.1650/ CONDOR-16-63.1

Jimenéz, J. E., Jahn, A. E., Rozzi, R., \& Seavy, N. E. (2016). First documented migration of individual White-Crested Elaenias (Elaenia albiceps chilensis) in South America. The Wilson Journal of Ornithology, 128, 419-425. https://doi. org/10.1163/187529271X00756

Johnson, J. A., Matsuoka, S. M., Tessler, D. F., Greenberg, R., \& Fox, J. W. (2012) Identifying migratory pathways used by Rusty Blackbirds breeding in southcentral Alaska. The Wilson Journal of Ornithology, 124, 698-703. https://doi. org/10.1676/1559-4491-124.4.698

Koleček, J., Procházka, P., El-Arabany, N., Tarka, M., Ilieva, M., Hahn, S., ... Hansson, B. (2016). Cross-continental migratory connectivity and spatiotemporal migratory patterns in the great reed warbler. Journal of Avian Biology, 47, 756-767. https://doi.org/10.1111/jav.00929

Laughlin, A. J., Taylor, C. M., Bradley, D. W., LeClair, D., Clark, R. G., Dawson, R. D., ... Norris, D. R. (2013). Integrating information from geolocators, weather radar, and citizen science to uncover a key stopover area of an aerial insectivore. The Auk, 130, 230-239. https://doi.org/10.1525/auk.2013.12229

Lemke, H. W., Tarka, M., Klaassen, R. H. G., Åkesson, M., Bensch, S., Hasselquist, D., \& Hansson, B. (2013). Annual cycle and migration strategies of a trans-Saharan migratory songbird: A geolocator study in the great reed warbler. PLOS ONE, 8, e79209. https://doi.org/10.1371/journal.pone.0079209

Liechti, F., Scandolara, C., Rubolini, D., Ambrosini, R., Korner-Nievergelt, F. Hahn, S., ... Saino, N. (2015). Timing of migration and residence areas during the non-breeding period of barn swallows Hirundo rustica in relation to sex and population. Journal of Avian Biology, 46, 254-265. https:// doi.org/10.1111/jav.00485

Liechti, F., Witvliet, W., Weber, R., \& Bächler, E. (2013). First evidence of a 200 day non-stop flight in a bird. Nature Communications, 4, 2554. https://doi. org/10.1038/ncomms3554

Lislevand, T., Briedis, M., Heggøy, O., \& Hahn, S. (2016). Seasonal migration strategies of Common Ringed Plovers Charadrius hiaticula. Ibis, 159, 225-229. https:// doi.org/10.1111/ibi.12424

Lislevand, T., Chutný, B., Byrkjedal, I., Pavel, V., Briedis, M., Adamík, P., \& Hahn, S. (2015). Red-spotted Bluethroats Luscinia s. svecica migrate along the IndoEuropean flyway: A geolocator study. Bird Study, 62, 508-515. https://doi.org/ 10.1080/00063657.2015.1077781
Lislevand, T., \& Hahn, S. (2013). Effects of geolocator deployment by using flexible leg-loop harnesses in a small wader. Wader Study Group Bulletin, 120, 108-113.

Macdonald, C. A., Mckinnon, E. A., Gilchrist, H. G., \& Love, O. P. (2016). Cold tolerance, and not earlier arrival on breeding grounds, explains why males winter further north in an Arctic-breeding songbird. Journal of Avian Biology, 47, 7-15. https://doi.org/10.1111/jav.00689

Matyjasiak, P., Rubolini, D., Romano, M., \& Saino, N. (2016). No short-term effects of geolocators on flight performance of an aerial insectivorous bird, the Barn Swallow (Hirundo rustica). Journal of Ornithology, 157, 653-661. https://doi. org/10.1007/s10336-015-1314-2

McNeil, S. E. M., Tracy, D., \& Cappello, C. D. (2015). Loop migration by a Western Yellow-billed Cuckoo wintering in the gran chaco. Western Birds, 46, 244-255.

Meier, C. M., Karaard, H., Aymí, R., Peev, S. G., Bächler, E., Weber, R., ... Liechti, F. (2018). What makes Alpine swift ascend at twilight? Novel geolocators reveal year-round flight behaviour. Behavioral Ecology and Sociobiology, 72, 45. https:// doi.org/10.1007/s00265-017-2438-6

Minton, C., Gosbell, K., Johns, P., Christie, M., Klaassen, M., Hassell, C., ... Fox, J. (2013). New insights from geolocators deployed on waders in Australia. Wader Study Group Bulletin, 120, 37-46.

Minton, C., Gosbell, K., Johns, P., Christie, M., Klaassen, M., Hassell, C., ... Fox, J. W. (2011). Geolocator studies on Ruddy Turnstones Arenaria interpres and Greater Sandplovers Charadrius leschenaultii in the East Asian- Australasia Flyway reveal widely different migration strategies. Wader Study Group Bulletin, 118, 87-96.

Nelson, A. R., Cormier, R. L., Humple, D. L., Scullen, J. C., Sehgal, R., \& Seavy, N. E. (2016). Migration patterns of San Francisco Bay Area Hermit Thrushes differ across a fine spatial scale. Animal Migration, 3, 1-13. https://doi.org/10.1515/ ami-2016-0001

Norevik, G., Åkesson, S., \& Hedenström, A. (2017). Migration strategies and annual space-use in an Afro- Palaearctic aerial insectivore - the European nightjar. Journal of Avian Biology, 48, 738-747. https://doi.org/10.1111/jav.01071

Ouwehand, J., Ahola, M. P., Ausems, A. N. M. A., Bridge, E. S., Burgess, M., Hahn, S., ... Both, C. (2016). Light-level geolocators reveal migratory connectivity in European populations of pied flycatchers Ficedula hypoleuca. Journal of Avian Biology, 47, 69-83. https://doi.org/10.1111/jav.00721

Ouwehand, J., \& Both, C. (2017). African departure rather than migration speed determines variation in spring arrival in pied flycatchers. Journal of Animal Ecology, 86, 88-97. https://doi.org/10.1111/1365-2656.12599

Ouwehand, J., \& Both, C. (2017). Data from: African departure rather than migration speed determines variation in spring arrival in pied flycatchers. Dryad Digital Depository. https://doi.org/10.5061/dryad.k6q68

Pakanen, V. M., Rönkä, N., Thomson, R. L., \& Koivula, K. (2015). No strong effects of leg-flagged geolocators on return rates or reproduction of a small long-distance migratory shorebird. Ornis Fennica, 92, 101-111.

Perlut, N. G. (2018). Prevalent transoceanic fall migration by a 30-gram songbird, the Bobolink. The Auk, 135, 992-997. https://doi.org/10.1642/AUK-18-56.1

Peterson, S. M., Streby, H. M., Kramer, G. R., Lehman, J. A., Buehler, D. A., \& Andersen, D. E. (2015). Geolocators on Golden-winged Warblers do not affect migratory ecology. The Condor, 117, 256-261. https://doi.org/10.1650/ CONDOR-14-200.1

Pillar, A. G., Marra, P. P., Flood, N. J., \& Reudink, M. W. (2016). Moult migration in Bullock's orioles (Icterus bullockii) confirmed by geolocators and stable isotope analysis. Journal of Ornithology, 157, 265-275. https://doi.org/10.1007/ s10336-015-1275-5

Procházka, P., Brlík, V., Yohannes, E., Meister, B., Auerswald, J., llieva, M., \& Hahn, S. (2018). Across a migratory divide: Divergent migration directions and nonbreeding grounds of Eurasian reed warblers revealed by geolocators and stable isotopes. Journal of Avian Biology, 49, jav-012516. https://doi.org/10.1111/ jav.01769

Renfrew, R. B., Kim, D., Perlut, N., Smith, J., Fox, J., \& Marra, P. P. (2013). Phenological matching across hemispheres in a long-distance migratory bird. Diversity and Distributions, 19, 1008-1019. https://doi.org/10.1111/ddi.12080

Ross, J. D., Bridge, E. S., Rozmarynowycz, M. J., \& Bingman, V. P. (2014). Individual variation in migratory path and behaviour among Eastern Lark Sparrows. Animal Migration, 2, 29-33. https://doi.org/10.2478/ami-2014-0003

Ryder, T. B., Fox, J. W., \& Marra, P. P. (2011). Estimating migratory connectivity of Gray Catbirds (Dumetella carolinensis) using geolocator and mark-recapture data. The Auk, 128, 448-453. https://doi.org/10.1525/auk.2011.11091

Salewski, V., Flade, M., Poluda, A., Kiljan, G., Liechti, F., Lisovski, S., \& Hahn, S. (2013). An unknown migration route of the "globally threatened" Aquatic Warbler revealed by geolocators. Journal of Ornithology, 154, 549-552. https://doi.org/10.1007/s10336-012-0912-5

Scandolara, C., Rubolini, D., Ambrosini, R., Caprioli, M., Hahn, S., Liechti, F., ... Saino, N. (2014). Impact of miniaturized geolocators on barn swallow Hirundo rustica fitness traits. Journal of Avian Biology, 45, 417-423. https://doi.org/10.1111/ jav.00412

Schmaljohann, H., Buchmann, M., Fox, J. W., \& Bairlein, F. (2012). Tracking migration routes and the annual cycle of a trans-Sahara songbird migrant. Behavioral Ecology and Sociobiology, 66, 915-922. https://doi.org/10.1007/ s00265-012-1340-5

Schmaljohann, H., Meier, C., Arlt, D., Bairlein, F., van Oosten, H., Morbey, Y. E., ... Eikenaar, C. (2016). Proximate causes of avian protandry differ between subspecies with contrasting migration challenges. Behavioral Ecology, 27, 321-331. https://doi.org/10.1093/beheco/arv160

Seavy, N. E., Humple, D. L., Cormier, R. L., \& Gardali, T. (2012). Establishing the breeding provenance of a temperate-wintering north American passerine, the golden-crowned sparrow, using light-level geolocation. PLOS ONE, 7, e34886. https://doi.org/10.1371/journal.pone.0034886 
Sechrist, J., Paxton, E., Ahlers, D., Doster, R., \& Ryan, V. M. (2012). One year of migration data for a western yellow-billed cuckoo. Western Birds, 43, 2-11.

Smith, M., Bolton, M., David, J., Summers, R. W., Ellis, P., \& Wilson, J. D. (2014) Short communication Geolocator tagging reveals Pacific migration of Rednecked Phalarope Phalaropus lobatus breeding in Scotland. Ibis, 156, 870873. https://doi.org/10.1111/ibi.12196

Stutchbury, B. J. M., Gow, E. A., Done, T., MacPherson, M., Fox, J. W., \& Stutchbury, B. J. M. (2010). Effects of post-breeding moult and energetic condition on timing of songbird migration into the tropics. Proceedings of the Royal Society B: Biological Sciences, 278, 131-137. https://doi.org/10.1098/ rspb.2010.1220

Stutchbury, B. J. M., Tarof, S. A., Done, T., Gow, E., Kramer, P. M., Tautin, J., .. Afanasyev, V. (2009). Tracking long-distance songbird migration by using geolocators. Science, 323, 896. https://doi.org/10.1126/science.1166664

Szép, T., Liechti, F., Nagy, K., Nagy, Z., \& Hahn, S. (2017). Discovering the migration and non-breeding areas of sand martins and house martins breeding in the Pannonian basin (central-eastern Europe). Journal of Avian Biology, 48, 114-122. https://doi.org/10.1111/jav.01339

Tøttrup, A. P., Klaassen, H. G., Strandberg, R., Thorup, K., Kristensen, M. W. Jørgensen, P. S., ... Alerstam, T. (2012). The annual cycle of a trans-equatoria Eurasian-African passerine migrant: Different spatio-temporal strategies for autumn and spring migration. Proceedings of the Royal Society B: Biologica Sciences, 279, 1009-1016. https://doi.org/10.1098/rspb.2011.1323

van Oosten, H. H., Versluijs, R., \& van Wijk, R. (2014). Twee Nederlandse Tapuiten in de Sahel: Trekroutes en winterlocaties ontrafeld. Limosa, 87, 168-172.

van Wijk, R. E., Schaub, M., Tolkmitt, D., Becker, D., \& Hahn, S. (2013). Short-distance migration of Wrynecks Jynx torquilla from Central European populations. Ibis, 155, 886-890. https://doi.org/10.1111/ibi.12083

van Wijk, R. E., Souchay, G., Jenni-Eiermann, S., Bauer, S., \& Schaub, M. (2015) No detectable effects of lightweight geolocators on a Palaearctic-African long distance migrant. Journal of Ornithology, 157, 255-264. https://doi.org/10.1007/ s10336-015-1274-6
Weiser, E. L., Lanctot, R. B., Brown, S. C., Alves, J. A., Battley, P. F., Bentzen, R., .. Sandercock, B. K. (2016). Effects of geolocators on hatching success, return rates, breeding movements, and change in body mass in 16 species of Arctic-breeding shorebirds. Movement Ecology, 4, 12. https://doi.org/10.1186/s40462-016-0077-6

Wellbrock, A. H. J., Bauch, C., Rozman, J., \& Witte, K. (2017). "Same procedure as last year?" - Repeatedly tracked swifts show individual consistency in migration pattern in successive years. Journal of Avian Biology, 48, 897-903. https://doi. org/10.1111/jav.01251

Woodworth, B. K., Newman, A. E. M., Turbek, S. P., Dossman, B. C., Hobson, K. A., Wassenaar, L. I., ... Norris, D. R. (2016). Differential migration and the link between winter latitude, timing of migration, and breeding in a songbird. Oecologia, 181, 413-422. https://doi.org/10.1007/s00442-015-3527-8

Xenophontos, M., Blackburn, E., \& Cresswell, W. (2017). Cyprus Wheatears Oenanthe cypriaca likely reach sub-Saharan African wintering grounds in a single migratory flight. Journal of Avian Biology, 48, 529-535. https://doi. org/10.1111/jav.01119

\section{SUPPORTING INFORMATION}

Additional supporting information may be found online in the Supporting Information section at the end of the article.

How to cite this article: Brlík $\mathrm{V}$, Koleček J, Burgess $\mathrm{M}$, et al. Weak effects of geolocators on small birds: A meta-analysis controlled for phylogeny and publication bias. J Anim Ecol. 2019;00:1-14. https://doi.org/10.1111/1365-2656.12962 